\title{
Ecological Resilience Restoration in the Watershed of the Hancang River
}

\author{
Xiangrong Kong1, Lin Wang2*, Gang Chen² \\ ${ }^{1}$ Urban Design, Cardiff University, Cardiff, UK \\ ${ }^{2}$ Department of Environmental Science and Technology, Ocean University of China, Qingdao, China \\ Email: *lwang@ouc.edu.cn
}

How to cite this paper: Kong, X.R., Wang, L. and Chen, G. (2020) Ecological Resilience Restoration in the Watershed of the Hancang River. Open Journal of Ecology, 10, 651-663.

https://doi.org/10.4236/oje.2020.1010040

Received: September 18, 2020

Accepted: October 26, 2020

Published: October 29, 2020

Copyright (C) 2020 by author(s) and Scientific Research Publishing Inc. This work is licensed under the Creative Commons Attribution International License (CC BY 4.0).

http://creativecommons.org/licenses/by/4.0/ (c) (i) Open Access

\begin{abstract}
Hancang River is a river on the eastern border of Jinan City. In recent years, with the development of cities, river flow has dropped sharply, river water has been polluted, and the ecological environment of the basin has declined. Improving the water ecological environment and enhancing the resilience of the water ecology of the river basin were set as the research goals, especially coupling of hydrological and ecological processes and the recycling of sewage resources. The "patch-corridor-matrix" theory of landscape ecology, the Least-cost distance model and the Arc Hydro Tools module of the ArcGIS platform were used to describe the river system and basin boundaries, optimize the current water network and the path network of the ecosystem. A novel ecological network and water network were proposed to form the final aquatic ecosystem, which combines the hydrological process with the ecosystem, and three decentralized wastewater treatment systems were designed to reduce the wastewater directly flowing into the river. The ecosystem resilience of the basin will be enhanced.
\end{abstract}

\section{Keywords}

Landscape Ecology, Ecological Network, Least-Cost Distance, Ecological Resilience

\section{Introduction}

"Ecological resilience" refers to the ability of an ecosystem to withstand and self-recover under the premise of maintaining essential life processes and structures without fundamental changes when subjected to external disturbances. Ian McHarg's "Design With Nature" was published in 1969, applying ecological thinking to landscape design, resulting in "design respecting nature" and per- 
fecting landscape design and ecology (Bo 2016) [1]. Integration of landscape and ecology opened up the scientific era of ecological landscape design, and also produced ecological design in a wider sense. The relationship between landscape pattern and ecological process is the key point of landscape ecology research (Fu et al. 2001) [2]. The principles and applications of landscape ecology are a comprehensive reflection of human activities and economic development in social society (Han et al. 2005) [3], including landscape structural diversity and spatial distribution (Hu et al. 2011) [4].

The concept of landscape pattern optimization is proposed on the basis of landscape ecological planning, land ecology, and computer technology. By adjusting and optimizing the distribution of different types of landscapes in space and quantity, the ecological benefits are maximized (Liu 2012; Wu 2002) [5] [6]. The purpose of land use planning is to optimize the landscape pattern. For example, agricultural land use research has evolved into a wider and more practical urban land, agro-forestry and animal husbandry land, tourism and rural residential land (Qin 2007; Shen 1989; Wei Wei 2009; Yue 2007) [7] [8] [9] [10].

Although some achievements have been made in the study of landscape ecology, the research on landscape pattern optimization is still in primary stage. Its theory, methods, and principles are not very available, and the concept has not been clearly defined (Vannote et al. 1980). [11] Optimizing the landscape pattern while ensuring that the landscape pattern plays a decisive role in ecological development in the landscape, attention should also be paid to the role of ecology in adjusting and maintaining the landscape pattern (Word 1898). [12] Based on a comprehensive understanding of landscape patterns, functions, and ecological processes, the establishment of critical landscape components or combinations that can control ecological engineering and improve ecological resilience is of guiding significance for improving regional ecological functions and maintaining regional ecological environment security.

\section{Materials and Methods}

Optimization of landscape pattern with common methods of improving ecological resilience includes conceptual model method, mathematical model method, computer space simulation, etc. (Han 2005) [3]. Knaapen considers the Least-cost Distance Model as the basis for landscape pattern optimization (Seppelt 2002) [13], To reveal the relationship between landscape patterns and ecological processes and functions (Vannote 1980; Wu 2002; Seppelt 2002) [6] [11] [13]. The least-cost distance model is used to calculate "effective distance", a measure for distance modified with the cost to move between habitat patches based on detailed geographical information on the landscape as well as behavioural aspects of the organisms studied (Simberloff 1969; Macarthur 2001) [14].

The ecological network is the first to describe the characteristics of the network structure in the landscape using graphic theory and methods since the 1990s. Dean Urban and his team have emphasized the pattern of corridors and 
the connectivity of the landscape, which has become a new method for landscape planning (Bunn 2000; Keitt 1997; Urban 2001) [15] [16] [17]. This method can be used to extract urban green areas and reconstruct urban green systems, and re-establish links with important natural resources outside urban areas (Ignatieva 2017) [18].

In the natural state, the river system is the most important ecological corridor. By connecting the erosion and sedimentation processes, the river system is the main driving force for the evolution of the ground landscape in multiple temporal and spatial scales (Poole 2002) [19]. In human-dominated landscapes, transportation networks such as roads and railways, shipping routes and air routes are the main networks of human society and modern landscapes (Abry 2002) [20]. The main function of the corridor network is to strengthen horizontal flow and cross-landscape connections (Bennett 2003) [21].

GIS are computerized information systems, containing hardware, software and data. A GIS provides structures and tools for capturing, storing, analysing, modelling, transforming and presenting spatial and attribute data referenced to the Earth (Longley et al. 2015) [22]. This ability to link spatial and attribute data is central to many of the needs of landscape planning, especially because it also offers scope for integrating information collected for different geographical units.

Based on the "patch-corridor-matrix" theory, the characteristics of the landscape pattern were abstracted by analyzing and identifying the ecological source, ecological corridor, ecological node, and ecological matrix of the watershed landscape. Using the concept of ecological network and GIS (Geographic Information System) technology, with least-cost distance, the landscape ecology of the study area is optimized, and a landscape ecological network is formed to improve the ecological resilience of the small watershed of the Hancang River.

\section{The Current Status of the Watershed of the Hancang River}

Hancang River is located at Licheng District, east of Jinan City. The length of Hancang River is about $24.5 \mathrm{~km}$. It originates from the valley of Yanpengwo Village in Licheng District and flows into Xiaoqing River in the east of Qujiazhuang, as shown in Figure 1. The northern part of the river basin is mainly cultivated land for wheat and corn. The central region has a high degree of urbanization, with residential areas and schools. The southern mountain area contains a large amount of forest land, grassland, scattered villages and cultivated land. The total area of the river basin is about $99 \mathrm{~km}^{2}$. The Hancang River is formed by the drainage of rain and floods in the southern mountainous areas, and the water volume of the river fluctuates greatly. At the beginning of this century, the river has water all year round. In recent years, there is no flow in the River. Affected by the north-south topography of the basin, the width of channels of the Hancang River varies from south to north, and gullies form in the southern mountainous areas. The widest point of the channel is hundreds of meters. 


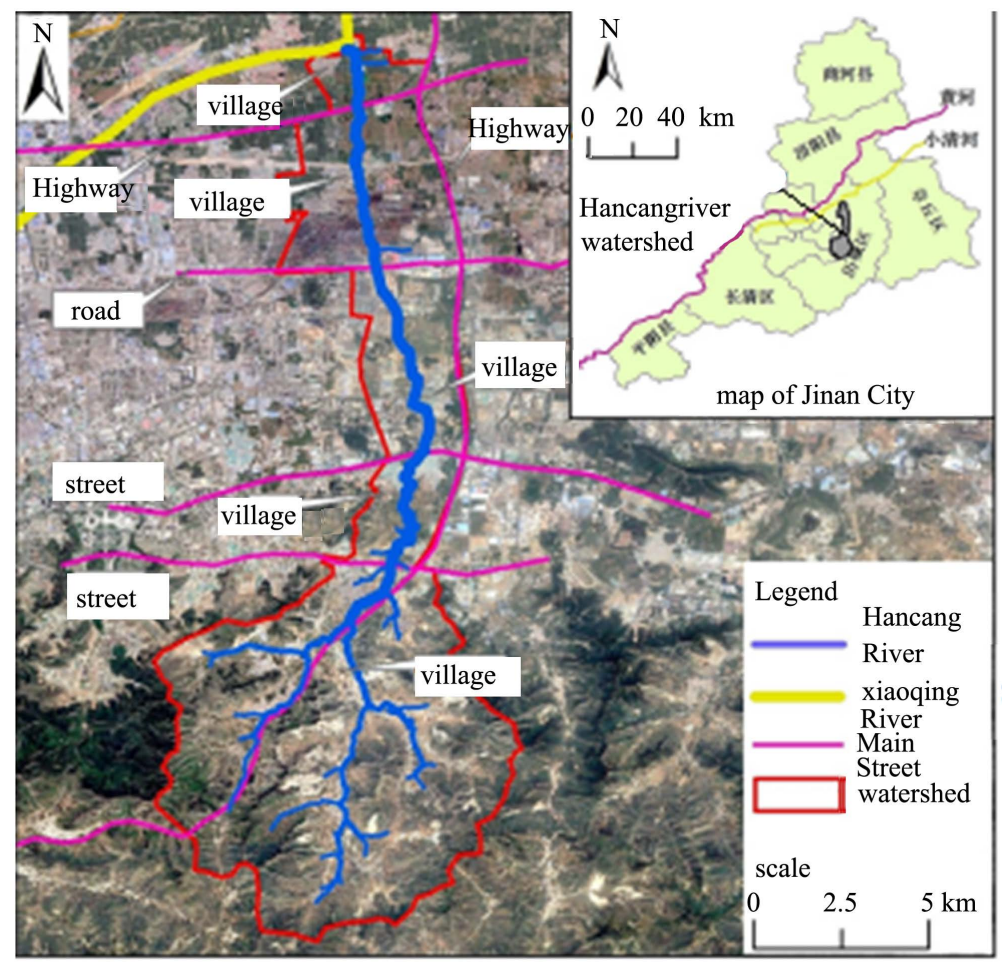

Figure 1. Location map of hancang small watershed.

Hancang River system and watershed boundary. Using the Arc Hydro Tools module of the ArcGIS platform, based on the DEM data, the hydrological characteristics of the river basin were extracted through water flow analysis, confluence analysis, river network generation, and watershed boundary division. The DEM data used is derived from the China Geospatial Data Cloud Platform. The DEM data is produced by processing the SRTM (Shuttle Topography Mission) radar image measured by the US space shuttle Endeavour. The current version is V4.1, which can be divided into SRTM1 and SRTM3 according to different accuracy. After processing, it generates DEM data products with $30 \mathrm{~m}$ and $90 \mathrm{~m}$ accuracy, respectively (Valeriano 2006). The DEM data used is identified as strm_60_05, with $35^{\circ}-40^{\circ}$ of north latitude and $115^{\circ}-120^{\circ}$ of east longitude. The data resolution is 30 meters. In order to improve the efficiency of data analysis, the DEM data should be moderated before hydrological analysis, remove some areas.

Hydrographic feature was extracted by using Arc Hydro Tools module. The threshold was adjusted through multiple iterative feedbacks, and when the threshold was 400, the result was finally determined as the water system extraction. Considering the influence of buildings, roads, pipe networks and other factors on the urban runoff path, the landsat8 OLI_TIRS image map with a resolution of $30 \mathrm{~m}$ was used to obtain the final water system distribution. After the boundaries of the catchment area included in the small watershed are determined, all the catchment areas can be summarized to obtain the research scope of the Hancang River catchment, as shown in Figure 2. 


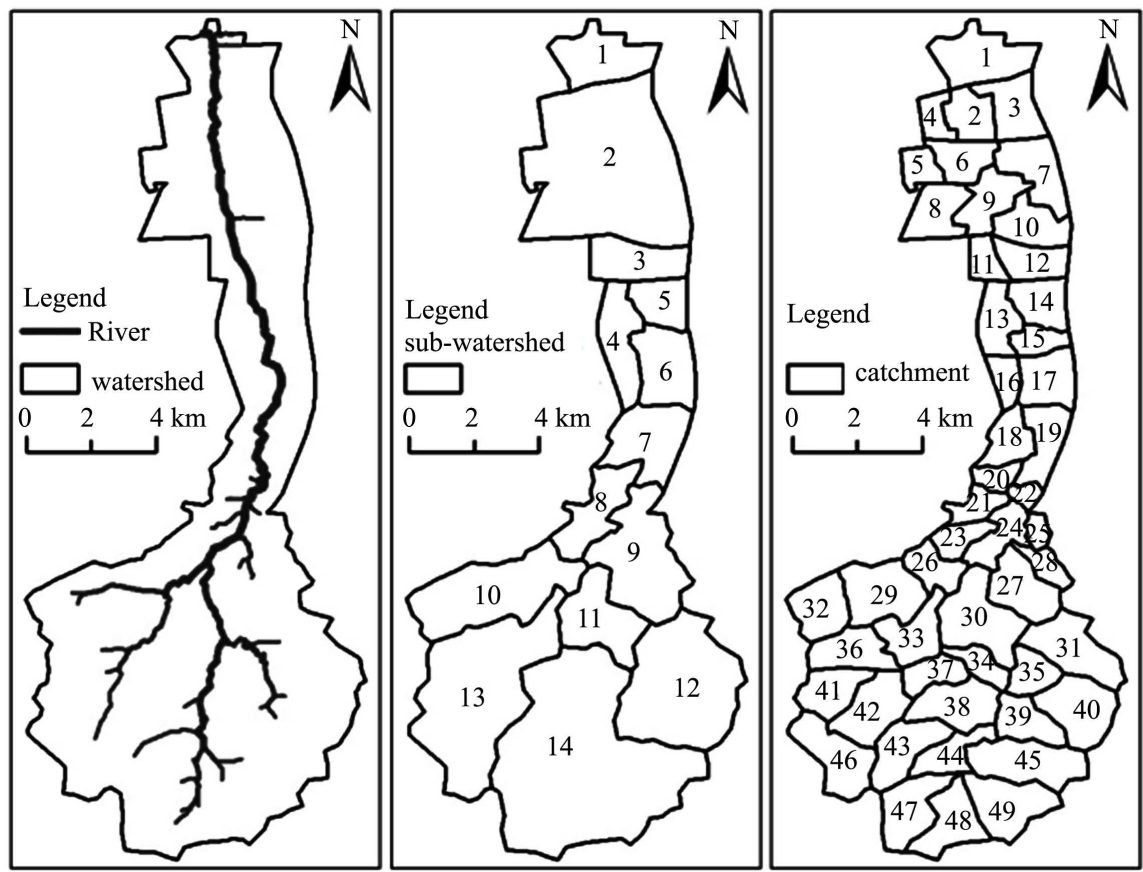

Figure 2. Water system and watershed of Hancang River.

Land-use types of the watershed of Hancang River. Visual interpretation method was used to extract the land-use types in research area. Refer to the "Technical Guide for Sponge City Construction" and the Land Use Classification System of the Chinese Academy of Sciences (MHUD 2015) [23], The land-use types in the watershed of the Hancang River are divided into 10 categories: building and residential area, cultivated land, forest land, factory building, open land, land under development, green land and grass, non-paved soil road, concrete or asphalt road, and water body. The image data used for visual interpretation is Landsat 8 OLI_TIRS satellite data of the geospatial data cloud platform. This product contains 11 bands of imaging with a wavelength range of $0.43 \mu \mathrm{m}$ to $12.51 \mu \mathrm{m}$, The image time is April 17, 2018, the image resolution is 30 meters. During the visual interpretation process, the data source provided by the 91 satellite image platform was used as a reference for Marar Technologies' synthetic RGB image with a resolution of 3.8 meters. The statistical data of each land type are shown in Table 1. The total area of the watershed is $98.68 \mathrm{~km}^{2}$.

\section{The Least-Cost Distance Analysis}

Ecological flow is the functional flow of materials, energy, and information that reflects ecological relationships in the ecosystem. Its smooth circulation in space is the basis for a reasonable and stable landscape ecological pattern (Guo 2015) [24]. The circulation of the ecological flow needs to be overcome the resistance from different landscape elements. This process is often analyzed and simulated by using least-cost distance model. Based on the cost distance function in the spatial analysis module on the ArcGIS platform, calculate the least-cost distance of each landscape unit to the nearest ecological source, indicating the spanning 
Table 1. Area of different land-use types in the watershed of the Hancang River.

\begin{tabular}{cccccc}
\hline Land-Use Types & $\begin{array}{c}\text { Area } \\
\left(\mathrm{m}^{2}\right)\end{array}$ & $\begin{array}{c}\text { Rate } \\
(\%)\end{array}$ & Land-Use Types & Area $\left(\mathrm{m}^{2}\right)$ & $\begin{array}{c}\text { Rate } \\
(\%)\end{array}$ \\
\hline building and residential area & $9,486,787.25$ & 9.6 & Land under development & $7,341,090.81$ & 7.4 \\
cultivated land & $26,386,389.61$ & 26.7 & green land and grass & $12,039,284.91$ & 12.2 \\
$\quad$ Forest & $30,931,464.01$ & 31.3 & non-paved soil road & $1,147,280.26$ & 1.2 \\
Factory building & $8,052,580.86$ & 8.2 & concrete or asphalt road & $863,804.94$ & 0.9 \\
Open land & $2,234,735.72$ & 2.3 & Water body & $196,156.67$ & 0.2 \\
\hline
\end{tabular}

resistance of each landscape type. The main factors considered in the least-cost distance model are ecological source, distance and landscape characteristic resistance, the Calculated as follows:

$$
A_{i}=\sum B_{i j} \times C_{i}(i=1,2,3, \ldots, n ; j=1,2,3, \ldots, m)
$$

Of which:

$A_{i}-$ the least-cost of the $i$-th landscape component to the ecological source;

$B_{i j}-$ the spatial distance across the $i$-th landscape component to the $j$-th ecological source;

$C_{1}$-the resistance value of the $i$-th landscape component to the operation of ecological flow;

$n$-the total number of landscape components.

According to the classification of ecosystem service functions, based on the land-use types in the watershed of Hancang River, combined with the ecological service function value of each land-use type. The extracted results of land-use types were reclassified using ArGIS, the original land-use type of building and residential area, factory buildings, under development or recently developed area, non-paved soil pavement, concrete or asphalt pavement are merged into building lot, other land types were not merged and directly transformed into the corresponding landscape land types, and 6 types of landscapes in the watershed of the Hancang River were obtained, including water body, forest, grass land, cultivated land, construction land, and unused land. The value of the ecological service function per unit area of each landscape type is used as the criterion for the resistance value $(\mathrm{Ci})$. The higher the value of the ecological service function of the landscape type, the more complete its ecological function, the smoother the ecological flow in it, and the lower its resistance value (Sun 2018) [25]. The ecological service value per unit area of each landscape type was determined by the research results of Xie Gaodi, Chen Zhongxin, Yin Dengyu, etc. (Chen 2000; Xie 2003; Yin 2018). [26] [27] [28] Setting the resistance value of the landscape type with the highest ecological service value per unit area of the Hancang River Basin to 1; otherwise, setting the resistance value of the landscape type with the lowest ecological service value per unit area to 100 . Resistance values for other landscape types were obtained by interpolation, ranging from 1 - 100, the results as shown in Table 2. 
Table 2. The land-use types and resistance value in the watershed of the Hancang river.

\begin{tabular}{|c|c|c|c|}
\hline $\begin{array}{c}\text { Merged } \\
\text { Land-use type }\end{array}$ & Original Land-use type & $\begin{array}{l}\text { Ecological function } \\
\text { service value per unit } \\
\left.\text { area/(yuan } / \mathrm{hm}^{2} \cdot \text { year }\right)\end{array}$ & $\begin{array}{c}\text { Resistance } \\
\text { Value }\end{array}$ \\
\hline Water body & Water body & $99,666.2$ & 1 \\
\hline Forest & Forest & $61,799.6$ & 37 \\
\hline Gross Land & Green land and Gross & $25,647.3$ & 71 \\
\hline Cultivated Land & Cultivated Land & $17,361.9$ & 79 \\
\hline Building lot & $\begin{array}{l}\text { building and residential area, factory } \\
\text { buildings, under development or recently } \\
\text { developed area, non-paved soil pavement, } \\
\text { concrete or asphalt pavement }\end{array}$ & -5372.1 & 100 \\
\hline Open Land & Open Land & 3054.8 & 92 \\
\hline
\end{tabular}

\section{Ecological Source Identification}

In ecology, lands with natural ecological functions and have important ecosystem service value or fragile ecological environments are called "ecological sources" (Zheng 2016) [29]. The landscape patches with high value of ecological service were identified as "ecological sources", therefore, the grassland, woodland and water body in watersheds with a continuous area of more than $6 \times 10^{5}$ $\mathrm{m}^{2}$ identified by ArcGIS as ecological sources, as shown in Figure 3.

\section{Ecological Corridor Identification}

The ecological corridor is a low resistance channel between the two adjacent ecological sources and the easiest low-resistance channel to connect (Pan 2015) [30]. Ecological corridors are generally composed of two types of landscapes: forest land and water body with high value of ecological services, which can enhance the connectivity between the divided ecological sources and important patches, and improve the spatial ecological resilience. In ArcGIS software, select the ecological source area and set the resistance value of the landscape type, and use the cost distance function of spatial analysis to calculate the least cost distance of each landscape component to the nearest ecological source, as shown in Figure 3. The least-cost distance was analyzed by the hydrological analysis module of ArcGIS, the continuous resistance valleys between ecological sources were extracted, and ecological corridors built in the research area, as shown in Figure 4.

\section{Ecological Node Identification}

Ecological nodes are generally located in areas with weak ecological functions on ecological corridors. They play a decisive role in the ecological flows and have a greater impact on the continuity of the landscape ecosystem structure and the integrity of system functions. According to the principle of connectivity of landscape elements, the intersection of ecological corridors was extracted as the 


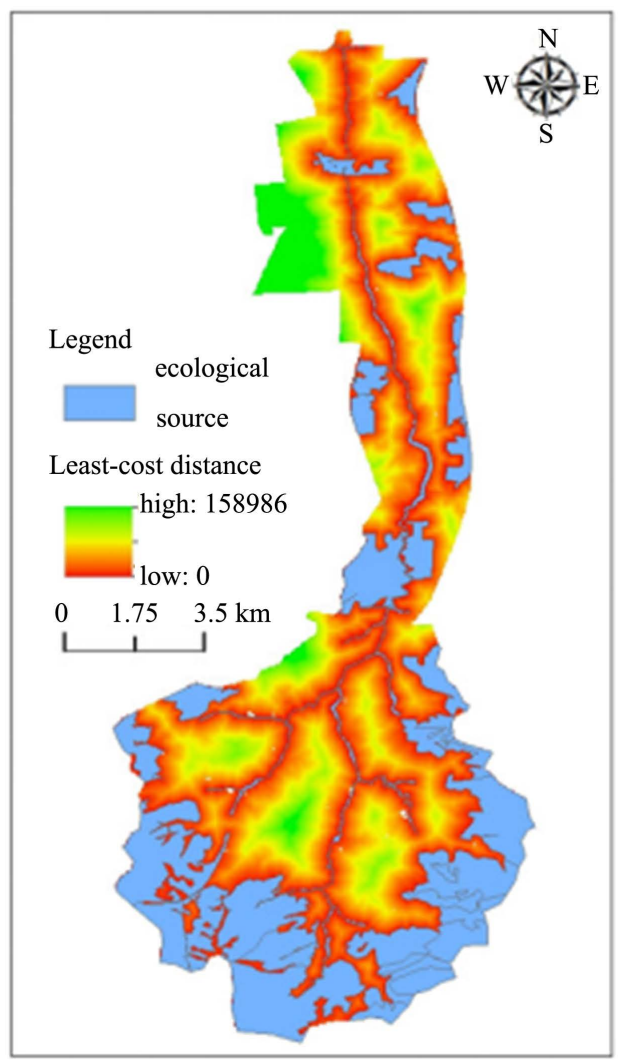

Figure 3. Least-cost distance in the watershed.

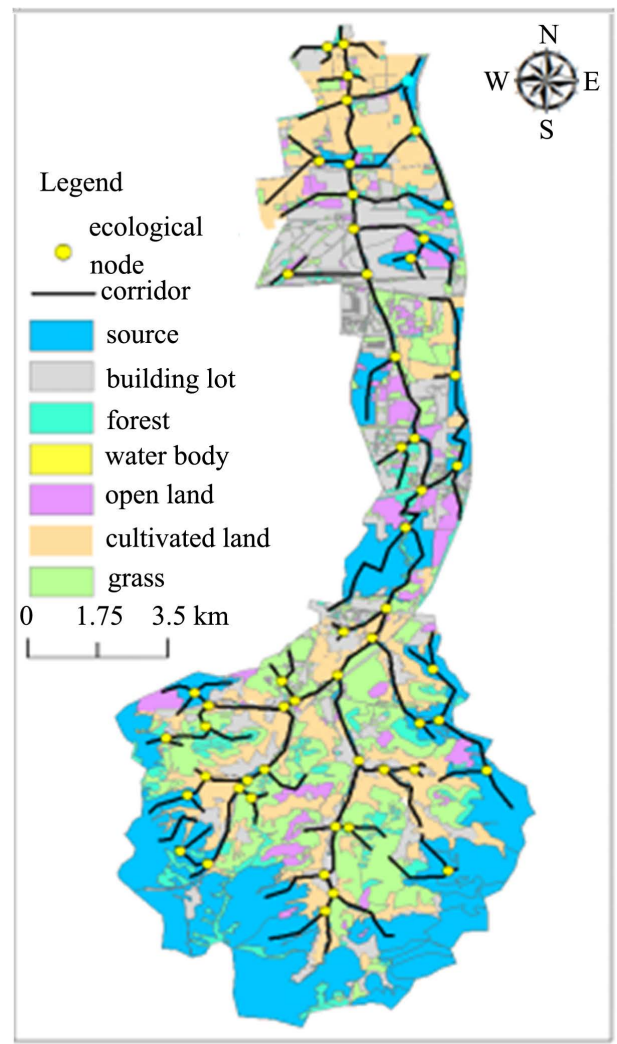

Figure 4. Ecological Network of the watershed. 
ecological node. There are 54 ecological nodes in the landscape ecological network of the Hancang River Basin, which are mainly distributed in the water bodies, cultivated land and building land, as shown in Figure 4.

\section{Ecological Matrix Identification}

The ecological matrix is very important in the ecological function. It is the ecological background of the corridors and nodes. It is the type of landscape that has the largest area proportion and has the strongest effect on landscape control. The area of forest in the watershed of Hancang River is $31.3 \%$. Therefore, the forest is the ecological substrate of the Hancang River Basin.

\section{Construction of Ecological Water Network System}

According to the catchment of the watershed of Hancang River, and the relationship between the water system and the landscape ecological network, the ecological source belongs to different catchment, and the corridor need connect most of the catchment, as shown in Figure 5. The water system extracted based on the geographical elevation information reflects the best hydrological cycle path in the natural state. If some locations with weak ecological functions in the existing water system are selected for dredging and widening, the ecological corridor function will be strengthened, the ecology will be improved, and ecological flows between sources will be running smoothly.

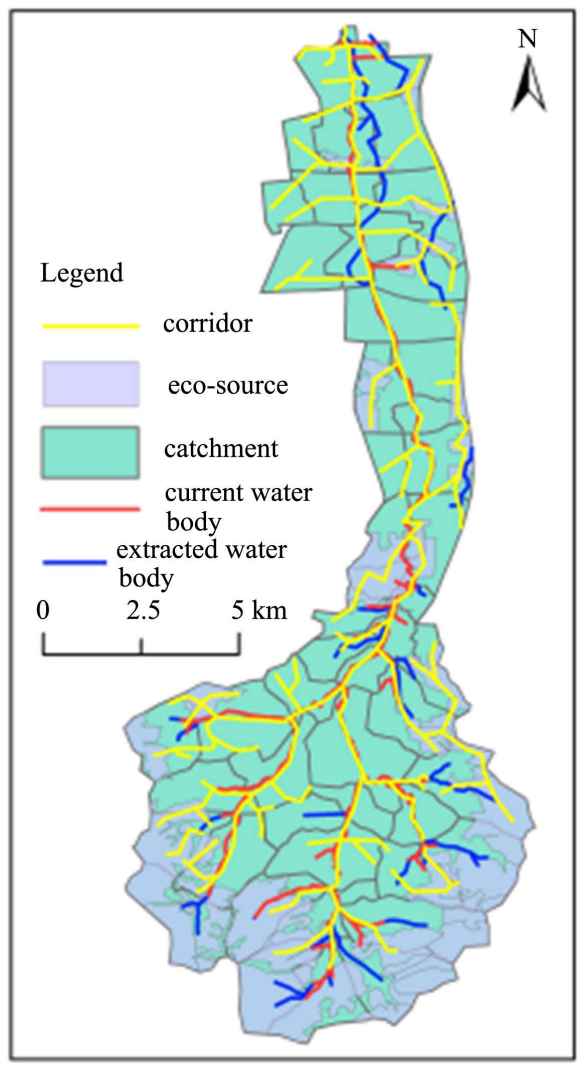

Figure 5. Location of catchment, water network and landscape network system. 
The layout of the ecological network needs to be improved by dredging the water network structure, and good water network connectivity is a necessary condition to ensure the smooth ecological flow in the system (Zhu 2005; Dong 2013) [31] [32]. Therefore, it is necessary to analyze the hydrological characteristics of the watershed of the Hancang River, a network structure that conforms to the current water system context, follows the surface hydrological cycle path, and the distribution characteristics of the catchment area will be identified, this network structure is the layout of water network. The layout of the network structure will be improved by restoring the connectivity of the water network, dredging the water circulation resistance nodes, and enhancing the ecological corridor function of the water system.

Using the ArcGIS hydrological analysis technology, the water network extracted by the DEM information has the characteristics of conforming to the natural hydrological cycle and meeting the terrain conditions of the corresponding river network construction. It can achieve the effect of dredging the water network connectivity with less human interference.

Therefore, the river section that needs to be dredged or connected, was selected from the water system extracted by hydrological analysis. The selected river section should also meet one of the following conditions: one is to connect the existing water system with the ecological source, and the other is to be located on the ecological corridor path in the study area.

The river section is determined according to the above conditions, and the layout of the ecological water network is shown in Figure 6. The total length of

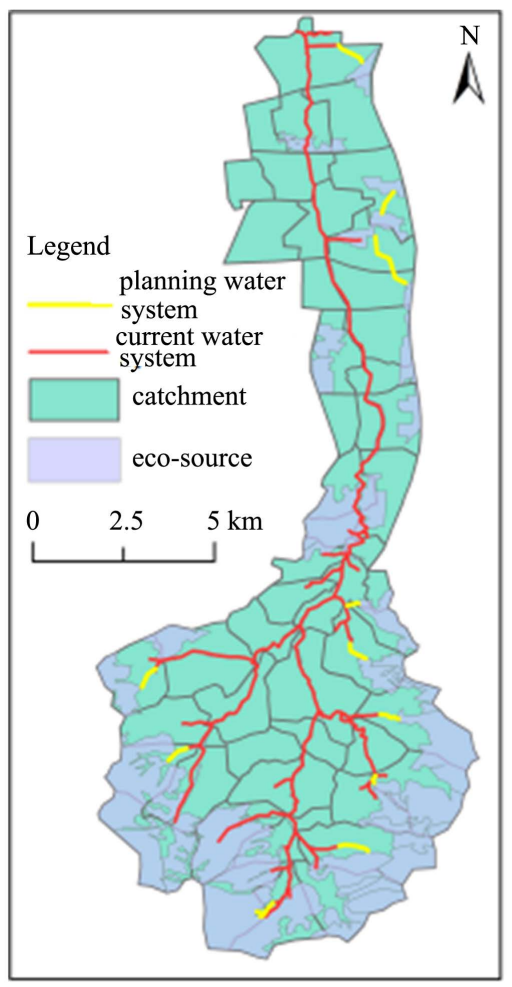

Figure 6. Current water network, and planning water channel. 
the ecological water network is $55.33 \mathrm{~km}$. Existing river channels that are in line with the layout of the ecological water network shall be retained and unblocked. The location of the ecological water network without river channels will be channelled by engineering measures to connect with the existing water system and corridors. The total channel is 12 sections, with a total length of $6.9 \mathrm{~km}$, as shown in Figure 6.

\section{Conclusion}

The least-cost distance model was used to analyze and extract the landscape ecological pattern of the watershed of the Hancang River. According to the relationship between the landscape ecological pattern and the water system in the watershed, enhancing the connectivity of the water system to various ecological sources and promoting the material energy flow in the watershed were processed to unblock and expand the weak link of ecological water system. The current water system and the expanded water system together constitute the ecological water network in the watershed of the Hancang River. The total length of the water network is $55.33 \mathrm{~km}$. Among them, there are 12 sections of the expanded river section that need to be connected to the existing water system and corridors through engineering measures, with a total length of $6.9 \mathrm{~km}$.

\section{Acknowledgements}

Thanks to Jinan Science and Technology Bureauf or its support of 500,000 yuan.

\section{Conflicts of Interest}

The authors declare no conflicts of interest regarding the publication of this paper.

\section{References}

[1] Yang, B. and Li, S.J. (2016) Design with Nature: Ian McHarg's Ecological Wisdom as Actionable and Practical Knowledge. Landscape and Urban Planning, 155, 21-32. https://doi.org/10.1016/j.landurbplan.2016.04.010

[2] Fu, B.J., Chen, L.D. and Ma, K.M. (2001) Principles and Applications of Landscape Ecology. Science Press, Beijing.

[3] Han, W.Q., Chang, Y. and Hu, Y.M. (2005) Research Progress in Landscape Pattern Optimization. Journal of Ecology, 12, 1487-1492

[4] Hu, J.L. (2011) Review of Landscape Pattern Evolution and Optimization. Anhui Agricultural Science Bulletin (First Half Monthly), 21, 92-94.

[5] Liu, J., Ye, J. and Yang, W. (2012) Landscape Pattern Optimization of Dianchi Basin Based on GIS. Journal of Natural Resources, 5, 801-808.

[6] Wu, J. and Hobbs, R. (2002) Key Issues and Research Priorities in Landscape Ecology: An Idiosyncratic Synthesis. Landscape Ecology, 17, 355-365. https://doi.org/10.1023/A:1020561630963

[7] Qin, X.D. and Min, Q.W. (2007) Application of Cellular Automata in Landscape Pattern Optimization. Resources Science, 4, 85-91. 
[8] Shen, G.F., Li, L.S., Fu, Z.R., et al. (1989) Agricultural Land Use Structure Optimization Model in Weishi County. Journal of Henan University (Natural Science Edition), 1, 59-65.

[9] Wei, W., Zhao, J. and Wang, X.F. (2009) Landscape Utilization Optimization in Shiyang River Basin Supported by GIS and RS. Geographical Sciences, 29, 750-753.

[10] Yue, D.P., Wang, J.P., Liu, Y.B., et al. (2007) GIS and RS Technology Supported Landscape Pattern Optimization in Northwest Beijing. Journal of Geography, 11, 1223-1231.

[11] Vannote, R.L., Minshall, G.W., Cummins, K.W., Sedell, J.R. and Cushing, C.E. (1980) The River Continuum Concept. Canadian Journal of Fisheries and Aquatic Sciences, 37, 130-137. https://doi.org/10.1139/f80-017

[12] Ward, J.V. (1989) The Four-Dimensional Nature of Lotic Ecosystems. Journal of the North American Benthological Society, 8, 2-8. https://doi.org/10.2307/1467397

[13] Seppelt, R. and Voinov, A. (2002) Optimization Methodology for Land Use Patterns Using Spatially Explicit Landscape Models. Ecological Modelling, 151, 125-142. https://doi.org/10.1016/S0304-3800(01)00455-0

[14] Simberloff, D.S. and Wilson, E.O. (1969) Experimental Zoogeography of Islands: The Colonization of Empty Islands. Ecology, 50, 278-296.

[15] Bunn, A.G., Urban, D.L. and Keitt, T.H. (2000) Landscape Connectivity: A Conservation Application of Graph Theory. Journal of Environmental Management, 59, 265-278. https://doi.org/10.1006/jema.2000.0373

[16] Keitt, T.H., Urban, D.L. and Milne, B.T. (1997) Managing Fragmented Landscapes: A Macroscopic Approach. Conservation Ecology, 1, 4. https://doi.org/10.5751/ES-00015-010104

[17] Urban, D. and Keitt, T. (2001) Landscape Connectivity: A Graph-Theoretic Perspective. Ecology, 82, 1205-1218.

[18] Ignatieva, M., Stewart, G.H. and Meurk, C. (2017) Planning and Design of Ecological Networks in Urban Areas. Landscape and Ecological Engineering, 7, 17-25. https://doi.org/10.1007/s11355-010-0143-y

[19] Poole, G.C. (2002) Fluvial Landscape Ecology: Addressing Uniqueness within the River Discontinuous. Freshwater Biology, 47, 64-66.

[20] Abry, P., Baraniuk, R., Flandrin, P., et al. (2002) The Multiscale Nature of Network Traffic: Discovery, Analysis, and Modeling. IEEE Signal Processing Magazine, 19, 28-46. https://doi.org/10.1109/79.998080

[21] Bennett, A.F. (2003) Linkages in the Landscape: The Role of Corridors and Connectivity in Wildlife Conservation. IUCN, Switzerland and Cambridge.

[22] Longley, P.A., Goodchild, M.F., Maguire, D.J., et al. (2015) Geographic Information Science and Systems. 4th Edition, Wiley, London.

https://doi.org/10.2305/IUCN.CH.2004.FR.1.en

[23] MHUD (2015) Technical Guide for Sponge City Construction-Low Impact Development Rainwater System Construction (Trial). Organized and Compiled by the Ministry of Housing and Urban-Rural Development of the People's Republic of China. China Construction Industry Press, Beijing.

[24] Guo, B.B., Yang, X.J., Jin, X.B., et al. (2015) A Review of the Research on the Composition and Analysis Methods of Ecological Flow. Chinese Journal of Ecology, 35, 1630-1639. https://doi.org/10.5846/stxb201305070969

[25] Sun, Y.X. (2018) Research on Construction of Ecological Network for Land Improvement Based on Granular Backstepping. China University of Geosciences, Wuhan. 
[26] Chen, Z.X. and Zhang, X.S. (2000) Value of China's Ecosystem Benefits. Chinese Science Bulletin, 45, 17-22.

[27] Xie, G.D., Lu, C.X., Leng, R.F., et al. (2003) Evaluation of Ecological Assets on the Qinghai-Tibet Plateau. Journal of Natural Resources, 18, 189-196.

[28] Yin, D.Y., Zhang, Q.J. and Zhai, T.T. (2018) Land Use Change in Shandong Province and Its Impact on the Value of Ecosystem Services. Bulletin of Soil and Water Conservation, 38, 134-143.

[29] Zhang, Y.J. and Yu, B.Y. (2016) Evaluation of Urban Ecological Network Space and Optimization of Its Pattern. Chinese Journal of Ecology, 36, 6969-6984.

[30] Pan, J.X. and Liu, X. (2015) Ecological Security Assessment and Pattern Optimization of Inland River Landscape Based on Spatial Principal Component and Minimum Cumulative Resistance Model: A Case Study in Ganzhou District, Zhangye City. Journal of Applied Ecology, 26, 3126-3136.

[31] Zhu, Q., Yu, K.J. and Li, D.H. (2005) Ecological Corridor Width in Landscape Planning. Chinese Journal of Ecology, No. 9, 2406-2412.

[32] Dong, Z.R. (2013) Ecological Restoration of Rivers. China Water Resources and Hydropower Press, Beijing. 